\title{
Factors of communication mix on social media and their role in forming customer experience and brand image
}

\author{
Radovan BACIK \\ University of Prešov, Prešov, Slovak Republic \\ radovan.bacik@unipo.sk \\ Richard FEDORKO \\ University of Prešov, Prešov, Slovak Republic \\ richard.fedorko@unipo.sk \\ Ludovit NASTISIN \\ University of Prešov, Prešov, Slovak Republic \\ ludovit.nastisin@unipo.sk \\ Beata GAVUROVA \\ Technical University of Košice, Košice, Slovak Republic \\ beata.gavurova@tuke.sk
}

\begin{abstract}
Building a brand is a long-term process and it also applies to the world of social media. It is said that building a good brand reputation takes years, but it can be ruin in a moment. Therefore, it is important to look responsibly at all the aspects that have a role in building a brand on social media. The actual experience with the brand on social media is able to significantly affect brand building. The study focuses on exploring brand-building relationships in the social media environment. We selected a set of factors to predict customer experience with the brand in a social media environment and then we examined the relationship between this customer experience and the perceived brand image. 476 respondents filled out the electronic questionnaire. The study puts the greatest emphasis on respondents aged 20 to 35 years. We used correlation analysis to investigate the relationships in this issue. Out of the seven investigated relationships, up to two cases with medium dependence were confirmed by the strong relevance of relationships. The results support the importance of using social media tools for branding purposes, because these tools are the ones with the greatest ability to influence the people's perception and attitude. It is also the fastest and one of the most personal ways to communicate with the customer. It happens in real time and it can convey the real emotion if performed right which all together help to trigger the user action. The findings of this study can guide marketing activities for companies to make the return on investment in social media as high as possible. The research offers a new perspective on selected factors and their role in creating social media experience and subsequently a brand image.
\end{abstract}

Keywords: brand, social media, customer experience, brand image, correlation analysis.

Please cite the article as follows: Bacik, R., Fedorko, R., Nastisin, L. \& Gavurova, B. (2018), "Factors of communication mix on social media and their role in forming customer experience and brand image", Management \& Marketing. Challenges for the Knowledge Society, Vol. 10, No. 2, pp. 1108-1118, DOI: 10.2478/mmcks-2018-0026. 


\section{Introduction}

Nowadays, social media are one of the most adequate tools to market our brand and stand out of the mass. When we do branding correctly, social media branding can help us connect to our target market in a useful way. Social media branding forms a natural but a fundamental part of our overall marketing efforts on major social platforms such as Facebook, Twitter and LinkedIn. Brand building has always been an important aspect of business, and this fact does not change; on the contrary, its importance is growing. The development of modern communication methods opens wide horizons of opportunities that companies can use in this process. Proper brand management is essential. We know about brands since the start of the entrepreneurship, but the progress also brings new opportunities and therefore the research in this area will never end. The positive customer experience with the brand is not the goal but the means by which the brand gains loyalty. This is a valuable aspect in today's changing world, and it is an improved image, which will make customers proud of branding. Customers will recommend it to others, which is a way of promotion and has one of the highest ability to persuade. It does not matter in which area the business operates; the goal is that customers should be aware of the brand. To be able to persuade our customers to perform an action goes hand in hand with brand credibility. Social media have the power to contribute to brand awareness in the online environment, including serving as the voice of a company that can communicate with the customer and create interaction, making the brand more accessible to existing and new customers. All brands want loyal customers, but building such a community is often challenging. For this reason, it is necessary to combine the principles of brand identity with its strategies in the social media. Raising brand awareness should be a top priority for managers. The social media are an excellent tool for this, as for example in December 2017, the number of people that on average log on to Facebook daily was more than 1.40 billion. This number is immense and ignoring such a mass would be unwise. Moreover, social media tools are truly capable of selecting people according to the target criteria of a variety of demographic species, activities, interests etc.

Many recent studies point to the growing trend of use and the importance of social media both from the point of view of customers and market operators. In the light of our research, it is appropriate to mention the research conducted by PerezVeta et al. (2018), who investigated the relationship between FPC factors (Fan page cues) and engagement on the website of the brand on social media platforms in the context of the tourism segment. These factors were created by social interactive values, visual appearance, and identity attractiveness, and in all cases, a strong engagement relationship with the site engagement has been confirmed. Kohli et al. (2015), who have explored building blocks of branding in relation to social media, presented another study. They argue that social media has a strong impact on brand management practices, both positively and negatively, if the essence of marketing on social media is misunderstood. Christou (2015) also presented an interesting study, in which he pointed out that trust in a social media brand is positively influencing brand loyalty. Seo and Park (2018) analyzed the effect of social media marketing activities (SMMAs) on brand equity and customer response in the aviation industry. It has been shown that SMMAs have a positive impact on the value of the equity and the customer response, pointing out that trendiness is the most important component of these 
activities. Kamboj et al. (2018) examines whether customer participation in social media brand communities affects brand trust, brand loyalty and branding co-creation. The findings revealed brand trust as a mediator between customer participation and brand loyalty in social media brand communities.

The goal of our study was to explore the issue of brand building in the social media environment. Based on the existing studies in the field, we have set the main goals of identifying the relationship between brand building in the social media environment and its impact on the customer. We were interested in the relationship between the selected factors of branding on social media and the social media experience of a brand customer.

\section{Literature review}

The essence of the branding concept is based on product marketing. The objective is to distinguish the product from its competitors or to give the buyer a specific form of preference for these goods (Knox, Bickerton, 2003; Korcsmaros et al., 2016.). Strizhakova, Price (2008), Srivastava, Gregory (2010) and Kapferer (2008) claim that the brand strategy is created by the company that sells the product or service in order to place and identify its brand. The products and services should attract the potential customer and increase profitability. Brand awareness is also important. Knox and Bickerton (2003) state that in the last decades, we can characterize branding by layers of incremental added value that relate to the essentials of a product or service in order to form and maintain peculiarities in a specific market. We can define branding as a name, concept, symbol, design, sign, more precisely their combination. The goal is to identify the products of one entity or group of entities and differentiate them from the others. It is not about targeting the target market instead of a competitor but identifying the subject as the right decision for the problem. According to Kapferer (2008) it is a strong difference, which must be supported by numerous actions. It is generally misconceived that the brand is equal to a logo that falls under that term but is only part of the brand strategy. Its role is to provide buyers with a recognition symbol for a particular product type, service or destination.

Brand building affects many aspects, which help the goods or services to be successful and effective on the market. It can strengthen the positive reputation; loyalty and support the perception of greater value and help buyers realize that their world is governed by the same values (Healey, 2008). The role of building a brand is to create a positive experience in the minds of customers. The brand represents a great idea or system of conviction that the customer regards as unique and beneficial to him. It affects customer satisfaction and it is a never-ending process (Kaputa, 2010; Frankovský et al., 2015). In addition, Keller (2009) claims that the brand and what it represents is the most important advantage of the company and is therefore the basis of a competitive advantage and profit. These statements show a clear assumption of the significance and benefits of having a strong and unforgettable brand.

As with the marketing strategy, the brand strategy also applies to the fact that there is no right version of the branding strategy. Each brand is unique and requires remarkable steps (Štefko et al, 2015). Moreover, managing brand in an online environment requires not only strong internal and external communication but also 
the placement of the term "brand" in the hierarchy of its values (Lipiäinen, Karjaluoto, 2015).

We can characterize the brand image by customer brand perception. The goal of strategic work with the image of the brand is to make sure customers have strong and decisive associations with a specific brand in their minds. Branding usually consists of several concepts: perception, because the brand is perceived; knowledge, because the mark is appreciated by knowledge, attitude, because users constantly perceive and evaluate their perceptions because of which they shape their brand attitudes (Aaker and Joachimsthaler, 2009; Heding et al. 2009). The survey has shown that the customer's attitude towards brand image has a positive impact on their willingness to buy goods or services (Chao-Sen, 2015).

The speed has changed drastically at which a message spreads. A message of a brand can be destroyed in a moment. Viral means power, social media is cool and loved, and customers have the strong desire to have control over their actions. Everything a brand do, its reputation can be affected immediately, it does not take months nor days. Social effort should be measured in minutes, not hours or days. Everybody can access it (Chao-Sen, 2015). Everybody can control it. Social media, the rapid influx of broadband, internet on mobile -the idea of influencers and brand message drivers is changing. Even a year ago, we used to talk about "sneezers" and "key influencers" in the online environment. Today, anybody can be an influencer with the help of just a usual device like a cellphone or a notebook. This way they can change the attitudes of others. And it's here for everyone to empower it. Ways of reactions of target audiences to brand messages change. The pattern of message absorption, interpretation and acceptance is also rapidly changing (Lipiäinen, Karjaluoto, 2015). What is trending is defined by the audience not by the marketing agency or any other entity. Their only choice is to accept it and adapt. All the ongoing changes on the social media platforms indicates the way the user behave in this environment and that the most important thing to take in consideration (Mahajan, 2012).

However, despite many existing knowledge about this area, there is scope for improving the knowledge of the effects of important factors on the customer experience with the brand. This paper address couple of them and tries to bridge the gap among those and intangible nature of such experience.

\section{Methodology and database}

In this research, we focused on selected factors potentially affecting branding in the social media environment in the Slovak market conditions. We chose the individual factors based on a prior review of existing knowledge in this field. In order to be more precise, we selected six factors (the regularity and relevancy of the content added, the appropriate form of SM communication, visual presentation, publication at a particular time, and the use of social media mix) in relation to social media user experience.

Based on this assumption, we worked with the following list of goals: to analyze the relationship between selected factors affecting branding of brands in social media and the customer experience with the brand. We also wanted to identify the relationship between this experience and the perceived brand image. 
The established research goal served as a basis for the following research hypotheses:

Hypothesis no. 1: There exists a statistically significant correlation between the regularity of adding brand content to social media and perceived customer experience.

Hypothesis no. 2: There exists a statistically significant correlation between the relevance of brand content added to social media and perceived customer experience.

Hypothesis no. 3: There exists a statistically significant correlation between social media brand communication and perceived customer experience.

Hypothesis no. 4: There exists a statistically significant correlation between the visual presentation of social media brands and the perceived customer experience.

Hypothesis no. 5: There exists a statistically significant correlation between the publication of brand content on social media at a particular time and perceived customer experience.

Hypothesis no. 6: There exists a statistically significant correlation between using a mix of multiple social media brands and perceived customer experience.

Hypothesis no. 7: There exists a statistically significant correlation between the positive experience of the customer with the brand and with the brand image in the social media environment.

The online questionnaire was used to obtain the primary data that are needed for further investigation. The primary task was to get to know the opinions of respondents and the way they perceive the matter. Multiple online channel distribution of the questionnaire was used. In specific we used e-mail, CTA links and online forums. However, we mostly use social networks to spread the questionnaire. Social network administrators and social platform administrators have been addressed for cooperation on this research and for the dissemination of this voluntary questionnaire. Our dataset consisted of random active users of social media who have an account on at least one of the before-mentioned social media, more precisely Facebook, Twitter, LinkedIn, YouTube, Pinterest, Google+, Instagram, Snapchat, and Tumblr. Being an active user of social media was mandatory requirement. All questionnaires that did not meet this condition were excluded from the survey.

Data collection took place during the second quarter of 2016. We consider the dataset to be relevant, since it is only two years old. It focuses on the subjective perception of respondents' problems and not on how the factors reflect the actual algorithm that is valid on the Facebook social network. The trend of changes in the algorithms and in the rules it uses is really fast, but the change of people's attitudes to the chosen area is not that fast. Therefore even scope of two years is not a case of results being outdated. As mentioned before, main accent is placed on intangible nature of experience and the way it happens cannot change in the matter of years. Such a change took at least couple decades to happen.

\section{The specification of the sample of respondents}

We came to the examination of 476 valid questionnaires. People under the age of 21 were the most $(23.94 \% ; \mathrm{N}=114)$. Next was a group of respondents from 28 to 31 years old $(22.90 \% ; \mathrm{N}=109)$. The third largest group was respondents aged 25 to 27 years $(18.28 \% ; \mathrm{N}=87)$, and those aged 22 to 24 years $(18.07 \%$; $=86)$. The smallest group was respondents aged 32 years old and older $(16.81 \%$; $=80)$. 
Distribution in terms of gender was almost even, although female had little predominance $(52.10 \%$; $=248)$ against males $(47.90 \% ; \mathrm{N}=228)$. In the case of education, the most numerous group was respondents with second degree high school education (33.82\%; $\mathrm{N}=161$ ), next it were respondents with secondary school education $(32.57 \% ; \mathrm{N}=155)$ and first degree high school education $(26.26 \%$; $\mathrm{N}=125$ ). Only minimum shares represented other educational groups. Employed people formed the largest group of respondents in case of social status $(42.01 \%$; $\mathrm{N}=200)$, next group were students (41.39\%; $\mathrm{N}=197)$ followed by entrepreneurs ( $9.88 \% ; \mathrm{N}=47$ ) and unemployed come last (6.72\%; $\mathrm{N}=32$ ).

Our analysis is based on the scale of ordinal data which does not satisfy the second condition of Kendall's $\tau$, therefore we have chosen correlations analysis and gamma coefficient. 5-Likert scale was used for the questionnaire. Selected coefficient interprets dependence within the interval from values of -1 to 1 . Ideal opposite dependency is positioned at value of -1 and ideal dependency is positioned at value of 1 . There are multiple scales regarding the evaluation of approximation. We have selected gamma coefficient interpretation as follows: weak dependency $(0.01-0.2)$, medium dependency $(0.2-0.3)$, strong dependency $(0.3-0.6)$ and very strong dependency ( 0.6 and higher).

\section{Results}

When evaluating the results of the analyses, we were interested in finding out which specific social media tools were used by respondents. The results confirmed the widest use of the world's most popular social network Facebook. Worldwide, there are more than 2.13 billion monthly active Facebook users for Q4 2017. (Noyes, 2018) This is why Facebook is one of the strongest brand building tools in this environment. We can see a more significant representation by the YouTube social network, reported by more than half of respondents. Considering almost 5 billion videos are watched on Youtube every single day (Noyes, 2018), it also has its place among most powerful tools. Other instruments showed lower proportions as shown in Figure 1.

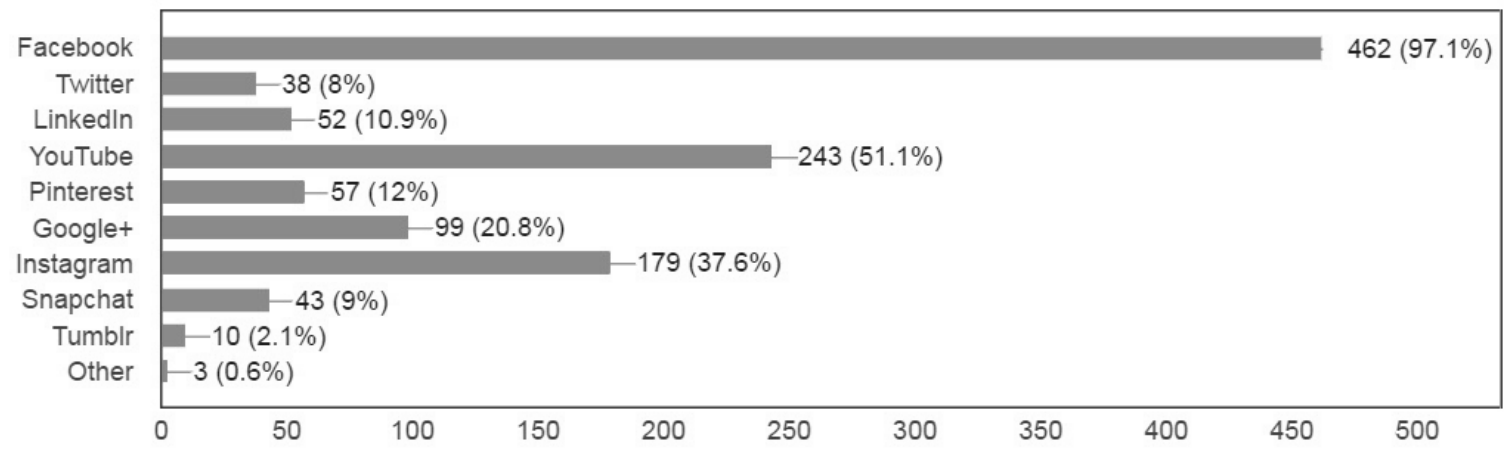

Figure 1. Preference of social media

Source: Authors' own results.

The frequency of social media use has also been taken into account when examining the given issue. The vast majority of the respondents use these tools up to several times a day $(79.41 \%, \mathrm{~N}=378)$, only one fifth of respondents $(18.49 \%, \mathrm{~N}=88)$ use it once a day and finally, once a week, they were only used by the minimum number of the respondents $(2.10 \%, \mathrm{~N}=10)$. Respondents responded to the question of the 
importance of brand image in the largest number in the case of the option, "Somewhat agree" $(43.07 \%, \mathrm{~N}=205)$, the second most popular was "Strongly agree" $(27.73 \%$, $\mathrm{N}=132)$, followed by "Neither agree nor disagree" (15.95\%, $N=76)$, "Somewhat disagree" $(11.14 \%, \mathrm{~N}=53)$ and finally "Strongly disagree" $(2.10 \%, \mathrm{~N}=10)$.

Table 1. Positive influencing of customer experienced by selected branding factors on SM

\begin{tabular}{|c|c|c|c|c|c|}
\hline \multicolumn{6}{|c|}{ Scale $(\mathrm{N})$} \\
\hline Factors & $\begin{array}{l}\text { Strongly } \\
\text { disagree }\end{array}$ & $\begin{array}{c}\text { Somewhat } \\
\text { disagree }\end{array}$ & $\begin{array}{c}\text { Neither agree } \\
\text { nor disagree }\end{array}$ & $\begin{array}{c}\text { Somewhat } \\
\text { agree }\end{array}$ & $\begin{array}{c}\text { Strongly } \\
\text { agree }\end{array}$ \\
\hline $\mathrm{F}_{1}$ & 10 & 66 & 118 & 207 & 75 \\
\hline$F_{2}$ & 10 & 22 & 75 & 234 & 135 \\
\hline $\mathrm{F}_{3}$ & 12 & 38 & 98 & 224 & 104 \\
\hline $\mathrm{F}_{4}$ & 13 & 56 & 117 & 187 & 103 \\
\hline $\mathrm{F}_{5}$ & 45 & 106 & 181 & 103 & 41 \\
\hline $\mathrm{F}_{6}$ & 20 & 77 & 174 & 150 & 55 \\
\hline
\end{tabular}

Notes.: $N$ - number of respondents, $F 1$ - regularity of adding content, $F 2$ - relevance of added content, F3 appropriate form of social media communication, F4 - visual presentation, F5 - time of adding content to social media, F1 - using a mix of multiple social media tools

Source: Authors' own results.

Table 1 shows the absolute responses in relation to the positive influence of customer experience on social media by selected brand building factors in the social media environment. We see from the data that in all the factors, the apparent perception of this assumption is rather a positive perception. Only in the case of adding content at a particular time of the day is this trend not copied and shows almost equal Gaussian response pattern.

Because of the descriptive analysis of the data we have found, we have also proceeded to the statistical verification of the established hypotheses. Here we analyzed the relationship between selected branding factors in the social media environment and their relationship to the customer experience with the brand in the social media environment. We can see the result of the correlation analysis in Table 2.

Table 2. Correlation analysis of selected factors on SM and perceived customer experience

\begin{tabular}{cccc}
\hline Hypothesis & gamma value & $\begin{array}{c}\text { asympt. } \\
\text { Std. Error }\end{array}$ & asympt. Sign. \\
\hline $\mathrm{H}_{1}$ & 0.337 & 0.055 & 0.000 \\
$\mathrm{H}_{2}$ & 0.536 & 0.054 & 0.000 \\
$\mathrm{H}_{3}$ & 0.238 & 0.067 & 0.001 \\
$\mathrm{H}_{4}$ & 0.276 & 0.060 & 0.000 \\
$\mathrm{H}_{5}$ & 0.345 & 0.057 & 0.000 \\
$\mathrm{H}_{6}$ & 0.452 & 0.053 & 0.000
\end{tabular}

Source: Authors' own results.

We can see the output dependencies of selected factors and customer experience in the social media environment. The correlation coefficient $\gamma$, in addition to the hypotheses $\mathrm{H} 3$ and $\mathrm{H} 4$, shows a high association rate. In these two cases, this is only a medium degree of association. When comparing the $p$ value with a defined acceptance limit, it is clear that there is a statistically significant dependence of the positive 
customer experience with the brand on selected branding factors in all cases. It should be added, that in the case of $\mathrm{H} 1$ and $\mathrm{H} 5$ this is a very tight placement in the association rate of strong dependency since the values are close to its boundary with medium dependency. However it points on the fact that this part should be researched in more depth in the future.

Table 3. Correlation analysis between the positive experience and the image of the brand

\begin{tabular}{|c|c|c|c|c|c|c|}
\hline \multicolumn{7}{|c|}{ "The image of the brand is really important to me" } \\
\hline $\begin{array}{l}\text { "My experience with social } \\
\text { media is positive" }\end{array}$ & $\begin{array}{l}\text { Strongly } \\
\text { disagree }\end{array}$ & $\begin{array}{l}\text { Somewha } \\
\text { t disagr. }\end{array}$ & $\begin{array}{l}\text { Neither } \\
\text { ag. nor } \\
\text { disag. }\end{array}$ & $\begin{array}{l}\text { Somewha } \\
\text { t agree }\end{array}$ & $\begin{array}{l}\text { Strongly } \\
\text { agree }\end{array}$ & Total \\
\hline Strongly disagree & 3 & 2 & 0 & 2 & 2 & 9 \\
\hline Somewhat disagree & 4 & 10 & 1 & 8 & 4 & 27 \\
\hline Neither agree nor disagree & 1 & 8 & 19 & 24 & 13 & 65 \\
\hline Somewhat agree & 2 & 30 & 51 & 142 & 69 & 294 \\
\hline Strongly agree & 0 & 3 & 5 & 29 & 44 & 81 \\
\hline \multirow[t]{3}{*}{ Total } & 10 & 53 & 76 & 205 & 132 & 476 \\
\hline & gamma value & & $\begin{array}{r}\text { asympt. } \\
\text { Std. Error }\end{array}$ & & asympt. Sig & \\
\hline & 0.426 & & 0.059 & & 0.000 & \\
\hline
\end{tabular}

The analyzed hypothesis presents the relationship of the customer's positive brand social media experience and its impact on the perceived image of a brand. The association rate with an output value of 0.426 is also possible in this case to interpret as a strong dependency of brand image on the positive experience of a customer with a brand in a social media environment. A statistically significant association rate is also confirmed by the $\mathrm{p}=0$ value (Table 3 ).

This study shows a similar trend to that of Perez-Veta et al. (2018) confirming the importance of FPC factors, in which case a strong relationship was confirmed in four of the six factors. As Kohli et al. (2015) have confirmed the relationship of social media to brand management; we have focused on a narrower area, more precisely on brand image. However, the results co-operate with their findings and that there is a significant impact on the perceived image of the social media experience. According to Christou (2015), we should examine the loyalty instead of the brand. We can see a parallel here. Finally yet importantly, the findings of Seo and Park (2018) do not deny the relationship with brand value. These factors also play a role in his work.

\section{Conclusion}

In this article, we focused on the relationship between selected brand management factors in the social media environment and their impact on customer experience with the brand. In relation to these relationships, we have also examined the link between customer experience and perceived brand image. We confirmed that all the selected 
factors prove to be significant, although in two cases only the medium level of interest. In its social media activities, the brand must take care to ensure that its actions are stable and regular and do not have the so-called empty windows effect. However, the most important factor was the relevance of the content. It is not just about creating any content just to make something public. It must be relevant to the target audience, the audience must be interested about it, and it must have an added value. The company cannot expect people to subscribe to any content with pleasure just because they are taking content from that brand. Long-term publishing of irrelevant items in the result will be negative and then the target person may even have an interest in canceling the subscription. It is like a two-sided weapon. The brand should also communicate across the spectrum of its activities in a uniform way with its style, its personality. This gives people a sense of responsible brand from which they are willing to take the content. The visual presentation is connected with it. We can confirm that the image is worth a thousand words. We should not underestimate the visual side because in this environment, people often decide in a fraction of a second from a first view. For example, if we handle social media accounts in an indiscriminate and inconvenient way, a person does not even seek to find additional information even if that company could be the one with the solution he needs. If it does not interest him, he is immediately gone. It also turned out that it does not matter where social media activities take place. We need to know who is the audience of the company or more precisely the audience of the brand, what are its specifics of behavior at specific times of the day and accordingly adapt their activities in terms of both time and content. For example, we should note that in the morning and during the normal working day, people do not have enough time and they spend less time on social media, so there is no need to take a wider range of added content. Rather, simpler things would be appropriate, the processing of which requires only a minimal amount of time, and letting those things go in the evenings when people have more free time. Such situations can be many and may be different from this one, but we should take into account. With strong dependence, we showed that even the presence and activities of a company on multiple types of social media are beneficial for building its brand. However, we should do it very reasonably, because creating the account is not enough. Everyone should work responsibly, be active on it, and present themselves across all social media. In addition, here is where decision-makers have to consider what resources are available to manage social media activities, whether human, knowledge, time, or financial. There is no need to make use of all the possibilities, even at the expense of not being fully involved by the company. This case is not neutral but rather counterproductive and contributes to the deterioration of brand image perception. Just as the customer's experience with the brand influences loyalty, it is also an influential factor in creating its image. People use social media to communicate about everything. In addition, communication is important because it is how people perceive the brand or, its image is reflected there. We can identify and publicly present a positive perceived image, which of course contributes to improved brand awareness. For practical application, it is also important to be aware of the fact that customer experience is like a two-sided weapon. Although it is, true that if a person has a positive experience, so it positively affects his brand perception, its image. However, if this experience is negative, it will also be reflected in these areas. 
For example, it is very inappropriate if the company has its accounts in several social media but only takes care of some. If a person encounters to such an account "without life", he immediately changes his mind and then it is very difficult to make him change his mind again. It is important to recall that the results reflect the perceptions and preferences of, in particular, groups of people from the age 20 to 35, since they are very important for businesses, as they can directly influence their economic indicators. It is a limitation of this research. In the case of the young generation, these findings would be very different, but given the pace of progress and innovation in this area, it would be inappropriate to make any predictions. When this group reaches an economically productive age, it will run for several years, and in this context, it is too long time to change, modify, or discover something completely new. For future research, however, we also see the possibility to examine the role of these factors statistically and the image on social media in the overall context of branding.

\section{Acknowledgement}

This paper was created under the scientific research grant VEGA 1/0806/16 „Research on issues of consumer behavior of a new generation of customers with emphasis on identifying preferences and usability of mobile platforms in the process of ecommerce of the subjects localized predominantly on the Central European Market" and VEGA 1/0789/17 „Research of e-commerce with relation to dominant marketing practices and important characteristics of consumer behavior while using mobile device platforms."

\section{References}

Aaker, D. and Joachimsthaler, E. (2009), "Brand Leadership”, New York: Free Press Business.

Chao-sen, W. (2015), "A Study on Consumers'Attitude Towards Brand Image, Athletes'Endorsement, and Purchase Intention", International Journal of Organizational Innovation, Vol. 8, No. 2, pp. 233-253.

Frankovský, M., Birknerová, Z. and Zbihlejová, L. (2015), "Possibilities of identification of predictors of occurrence of cognitive distortions in managerial work", Polish Journal of Management Studies, Vol. 12, No. 2, pp. 69-78.

Healey, M. (2008), What is Branding? Singapore: Rotovision SA.

Heding, T., Knudtzen, Ch. and Bjerre, M. (2009), "Brand Management: Research, Theory and Practise", New York: Routledge.

Kapferer, J. N. (2008), "The New Strategic Brand Management: Creating and Sustaining Brand Equity Long Term", 4th Edition. London: Kogan Page.

Kaputa, C. (2010), "You are a Brand!”, Boston: Nicholas Brealey Publishing.

Keller, K. L. (2009), "Building Strong Brands in a Modern Marketing Communications Environment”, Journal of Marketing Communications, Vol. 15, No. 2-3, pp. 139155.

Knox, S. and Bickerton, D. (2003), "The Six Conventions of Corporate Branding" European Journal of Marketing, Vol. 37, No. 7-8, pp. 998-1016.

Korcsmaros, E., Mura, L. and Hevesi, A. (2016), "Selected aspects of business networks", Actual Problems of Economics, Vol. 186, No, 12, 147-156. 
Lipiäinen, H. S. M. and Karjaluoto, H. (2015), "Industrial branding in the digital age", The Journal of Business and Industrial Marketing, Vol 30, No. 6, pp. 733-741.

Mahajan, V. (2012), "The Arab World Unbound: Tapping into the Power of 350 Million Consumers", New York: John Wiley \& Sons.

Noyes, D. (2018), "Valuable social media statistics", [online]. Retrieved [2-3-2018]. Available at: https://zephoria.com/top-15-valuable-facebook-statistics/.

Štefko, R. et al. (2015), "Strategic Marketing Communication in Pilgrimage Tourism", Proceedings of the 3rd International Conference on Strategic Innovative Marketing (IC-SIM), Madrid: Elsiever, pp. 423-430.

Strizhakova, Y., Coulter, R. and Price, L. (2008), "The Meanings of Branded Products: A Cross-National Scale Development and Meaning Assessment", International Journal of Research in Marketing, Vol. 25, No. 2, pp. 82-93.

Perez-vega, R., Taheri, B., Farrington, T. and O'Gorman, K. (2018), "On being attractive, social and visually appealing in social media: The effects of anthropomorphic tourism brands on Facebook fan pages", Tourism management, Vol. 66, No. 1, pp. 339-347.

Kohli, Ch., Suri, R. and Kapoor, A. (2015), "Will social media kill branding?", Business Horizons, Vol. 58, No. 1, pp. 35-44.

Christou, E. (2015), "Branding Social Media in the Travel Industry", Procedia - Social and Behavioral Sciences, Vol. 17, No. 5, pp. 607-614.

Seo, E. and Park, J. W. (2018), "A study on the effects of social media marketing activities on brand equity and customer response in the airline industry", Journal of Air Transport Management, Vol. 66, No. 1, pp. 36-41.

Kamboj, S., Sarmah, B., Gupta, S. and Dwivedi, Y. (2018), Examining branding cocreation in brand communities on social media: Applying the paradigm of Stimulus-Organism-Response", International Journal of Information Management, Vol. 39, No. 1, pp. 169-185. 